\title{
As escolhas de formação pessoal e profissional de um jovem protagonista responsável
}

\author{
Estevão de Souza
}

Resumo: O presente trabalho pretende relatar as escolhas de formação pessoal e profissional de um jovem protagonista responsável com base em pesquisa bibliográfica feita sobre o tema. Compreendeu-se como as distrações e as escolhas feitas diariamente influem diretamente nos resultados pessoais e profissionais do jovem. O jovem que consegue fazer escolhas alinhadas com sua autoconstrução colhe resultados importantes que reforçam sua base econômica.

Palavras-chave: Jovem; Escolhas; Protagonista; Base Econômica.

\section{Choices of personal and professional fostering of a responsible protagonist} young

Abstract: This paper aims to report the personal and professional fostering choices of a responsible protagonist young, based in a bibliographic research on the theme. It was understood how the distractions and the choices made daily directly influence on the personal and professional results of the young. The young that achieves to make choices aligned with his self-construction obtains important results that increase his economic basis.

Keywords: Youth; Choices; Protagonist; Economic Basis.

Las elecciones de formación personal y profesional de un joven protagonista responsable

Resumen: El presente trabajo pretende relatar las elecciones de formación personal y profesional de un joven protagonista responsable con base en investigación bibliográfica hecha sobre el tema. Se comprendió cómo las distracciones y las elecciones hechas diariamente influyen directamente en los resultados personales y profesionales del joven. El joven que consigue hacer elecciones ordenadas con su autoconstrucción obtiene resultados importantes que refuerzan su base económica.

Palabras clave: Joven; Elecciones; Protagonista; Base Económica.

\section{Introdução}

Este trabalho apresenta como temática as escolhas de formação pessoal e profissional do jovem protagonista responsável, delimitando a importância da formação séria visando um desenvolvimento pessoal e profissional de evidência protagonista 
responsável. A vida é feita de ciclos, passagens em fases de construção. Para um jovem tornar-se protagonista responsável deve constituir uma vida séria, de muito trabalho e estudo, aproveitando o tempo livre em atividades diversas e que de alguma forma consigam trazer ganho pessoal. A formação pessoal e profissional de um jovem decorre de um período de muitas dúvidas e distrações sendo difícil alcançar a capacidade de reconhecer que a fase de vida atual é base para o futuro, pilar para uma futura grandeza.

Durante todo o percurso formativo, o jovem passa por várias escolhas, que por mais simples que sejam, refletirão de alguma forma no futuro. O protagonismo responsável é uma escolha, um modo de encarar a vida em primeira pessoa, ou seja, consciente de seus atos e escopos de vida bem definidos. Todos os dias os jovens são postos a prova, podendo distrair-se por infinitos meios. Por isso, precisam estar atentos em seu objetivo. Para um jovem, é muito importante buscar desenvolver-se o mais cedo possível, dispor-se estudando, trabalhando e formando uma autonomia econômica.

Uma das fases de maior importância e de muitas dúvidas é o momento da escolha pelo lugar para começar a constituir uma vida profissional e de estudos. Minha motivação em escrever este trabalho é justamente por ter vivenciado, ainda recentemente, este período, reconhecer o quão difícil escolher em meio a tantas distrações. Trata-se de fazer escolhas que realmente proporcionem uma ascensão, optar em primeira pessoa, sem influências externas e alheias a si. Tenho tamanho apreço pela formação de jovens e é isso que me motiva detalhar de maneira simples um breve percurso, que está apenas no início, porém de alguma forma já possui diretivas visíveis e palpáveis.

Desse modo, a partir do momento em que tivermos jovens, protagonistas responsáveis a sociedade como um todo cresce, pois nós, jovens, seremos os futuros líderes, públicos e privados, que de alguma forma assumirão postos de gestão, mas, para isso é muito importante uma formação de valor.

No campo científico, procuro demonstrar estudos de grandes pensadores que demonstraram de fato o quão importante é a formação e a responsabilidade para um jovem, pois, "existe um ponto fundamental que interessa a todos: a nossa juventude... Para onde está caminhado hoje? Que potencial possui? E o que estamos fazendo para os nossos melhores jovens?" (MENEGHETTI, 2005, p. 83).

Assim, o presente artigo pretende trazer de forma simples citações de grandes autores e relatos vividos em fase da juventude. 


\title{
2 Fundamentação Teórica
}

A sociedade atual vive em um contexto de distrações, formas de alienação que na maioria das vezes não são percebidas, apenas executadas. Passamos por um processo de massificação, reproduzindo memes ${ }^{1}$ que nos são propostos todos os dias. As mais novas tendências de redes sociais, aplicativos para smartphones e suas tamanhas adesões, são uma prova de princípios formativos descontextualizados de uma fase de desenvolvimento. Temos também a mídia televisiva, rádios, jornais e outros meios que trazem constantemente informações, novos modelos a serem seguidos e que acabam desviando a atenção dos jovens para vaidades.

O cientista Acadêmico Professor Antonio Meneghetti aponta para a idade entre os 14 e 24 anos denominando-a como a "década de ouro", isto é, a fase com maior capacidade de formação intelectiva e prática, em que o jovem deveria desenvolver suas aptidões, pois é a fase onde há a maior capacidade de absorção de conhecimento. Em um capítulo do livro Psicologia Managerial ${ }^{2}$ a autora Bernabei (2011) traz cinco (5) pontos essenciais para um jovem que busca ser protagonista responsável visando desenvolver-se e constituindo uma base econômica:

1 - Um diploma;

2 - Saber ao menos uma língua estrangeira;

3 - Saber usar computador e internet;

4 - Especializar-se em um campo de interesse;

5 - Aprender falar em público e, imediatamente, reforçar a própria imagem.

1) O primeiro ponto elencado pela autora é o diploma.

\begin{abstract}
A graduação apenas nos orienta em determinados campos (médico, arquiteto, engenheiro etc.) Nos anos de 1970 e de 1980 parecia indispensável, mas hoje, em muitas áreas econômicas, não é mais considerado um requisito ou um critério de valor, busca-se mais o "saber fazer" (BERNABEI in.Psicologia Managerial, 2011p. 29).
\end{abstract}

O Diploma superior passou a ser um critério base de seleção profissional, portanto, quem não o possuir, estará automaticamente excluso de boas

\footnotetext{
1 “Informação reproduzida por meio de estereótipos. Não visa o crescimento do sujeito e leva-o à involução por meio da reprodução de pensamentos e atitudes." Para mais informações: MENEGHETTI, A. Dicionário de Ontopsicologia. Recanto Maestro: Ontopsicológica Editora Universitária, 2012, p. 162.

${ }^{2}$ Psicologia Managerial. Vários autores. 3. ed.. São Paulo: FOIL, 2011.
} 
oportunidades profissionais. Em muitos casos, as exigências vão além da graduação, sendo necessário o mestrado, doutorado, etc.

2) O segundo ponto e, não menos importante, é saber ao menos uma língua estrangeira, um requisito que, se não adquirido, pode privar o jovem de grandes possibilidades de trabalho, pois, em um mundo cada vez mais globalizado, em que contatos com pessoas de outros países se tornam rotineiros é necessário estar capacitado a responder de forma clara. A autora afirma:

\begin{abstract}
A língua mais usada no mundo nas relações comerciais, politicas e de informações é o inglês. "Como mínimo é preciso saber o inglês ou, ao menos, a língua para a qual o interesse da própria atividade é orientado" (BERNABEI in.Psicologia Managerial, 2011 p. 29b).
\end{abstract}

A língua inglesa, no mercado de trabalho é um dos critérios principais. Grandes multinacionais abrem oportunidades a jovens como estagiários, trainee, onde o diferencial da língua estrangeira é decisivo.

3) $\mathrm{O}$ terceiro ponto comenta aspectos importantes sobre saber usar o computador e a internet. As tecnologias atualmente são impulsoras de mercado, tudo gira através delas. Saber usar o computador, para a geração "Z” se tornou tão importante quanto o alfabeto aprendido na escola, todavia, com isso, surgem questões sérias sobre a gestão de conteúdos procurados por sites e redes sociais. Por haver tamanha facilidade e acesso aos conteúdos, muitas informações surgem, sendo elas negativas e positivas, para isso, é preciso estar atento e saber selecionar conteúdos verdadeiros, de fontes seguras e que façam relação ao processo de ascensão pessoal e profissional. A questão é que:

\footnotetext{
Estamos indo à chamada analfabetização digital, por isso, quem não aprendeu a usar os computadores, não o fará mais (ou fará com muito esforço) aumentando de modo exponencial a disparidade com aqueles que sabem usar e que, portanto, têm maior competitividade no mercado de trabalho. "Além disso, esse sistema está crescendo cada vez mais, a ponto tal de ser tornado indispensável em alguns campos." (BERNABEI in.Psicologia Managerial, 2011, p.30c).
}

4) $\mathrm{O}$ quarto ponto elencado pela autora é especializar-se em um campo de interesse. Nesta idade o desenvolvimento exige a experiência em várias atividades, se colocar em prática para conseguir ter uma noção de como e onde se adequar, 
adquirindo facilidade e interesse em desenvolver-se. Com base nas descobertas advindas da prática, se especializar, buscar informações, cursos que façam crescimento ao interesse profissional.

\begin{abstract}
Não precisa ser necessariamente aquele definitivo do próprio escopo geral, mas que dê uma eficiência de ganho constante e contínua atualização. Com o anulamento do espaço e do tempo, o saber fazer sem um posterior atualizar-se, torna-se, imediatamente, um não saber fazer. Seria necessário aprender ao menos uma ou duas coisas novas por dia no próprio campo especifico (BERNABEI in Psicologia Managerial, 2011, p. 29d).
\end{abstract}

5) Quinto e último ponto, saber falar em público e, imediatamente reforçar a própria imagem. Sempre quando se tem a tarefa de falar em público surge aquele frio na barriga, aquele medo de fazer, dizer alguma coisa errada e ser reprendido pelos ouvintes. Pesquisas apontam para o medo de falar em público como algo mais amplo que o medo da morte. Mas a partir do momento em que se desenvolve e pratica, torna-se uma atividade prazerosa e de grande valor profissional. Usar a capacidade de falar em público reforça a imagem pessoal.

\begin{abstract}
Na próxima vez que vocês sentirem a necessidade de falar e ficarem paralisados pensem simplesmente: "o que pode acontecer de tão grave se eu disser o que penso? O que pode acontecer de tão grave se pronunciar mal algumas palavras e esquecer uma frase?". O pior que habitualmente acontece é uma risadinha presa ou uma interrupção. O mais importante é sempre compreender o tipo e público diante do qual se está (BERNABEI in Psicologia Managerial, 201, p. 29e).
\end{abstract}

Os 5 pontos constituintes da base econômica, são verdadeiramente simples o entendimento, porém, o ato de desenvolver essas aptidões demanda seriedade, e empenho individual frente à própria vida pessoal e profissional.

Em meio a tantas distrações deparadas, a fase referente ao final do ensino médio, sem dúvida é constitui um dos momentos de maior indagação, preocupação e idealismos tolos que subitamente devem ser controlados. É neste momento que o jovem pode, por meio da dúvida, sabotar-se, perdendo tempo e, na maioria das vezes, fazer escolhas erradas.

No final de 2013 tive a felicidade de conhecer um dos lugares mais belos já visitados, não somente em termos de estética, mas pela formação dos jovens naquele local evidenciada. Consegui identificar resultados tão grandes em jovens 
iniciantes em sua formação. Aquilo me deixou provocado de modo a afirmar: "eu posso fazer mais!”.

Neste mesmo período estive em meio a uma grande escolha, sobre qual faculdade cursar. Sempre tive muito apreço pelas comunicações sociais e vinha com a ambição de ser aprovado em uma universidade federal que possuísse este seguimento de curso. Venho de família humilde que não teria como sustentar meus estudos em uma faculdade privada, portanto, era obrigado a entrar em uma instituição sem custo. Todavia, ao conhecer aquele lugar que me plantou um anseio e que fez mudar minha forma de pensamento, me senti provocado. Houve um jogo interno entre aquele espaço e meu interior que resultaram em informação positiva. Neste lugar, chamando Recanto Maestro, há uma das mais nobres instituições de ensino do mundo, a Antonio Meneghetti Faculdade. Assim, fiz minha opção e comecei a trilhar uma das melhores fases de minha vida: o início de uma graduação e meu primeiro trabalho. Comecei a entender por que motivo aquele recanto era tido como Maestro, mais que um local, um professor que ensina diariamente como ser, saber e fazer sempre mais.

\section{Método}

Com metodologia bibliográfica documental, este artigo relatou sobre a situação existencial de jovens considerando um relato pessoal, o meu, jovem na idade de 20 anos, graduando e profissional na área comercial e de marketing, em sintonia com trechos referenciados evidenciando a relação do jovem, sua vida pessoal e profissional.

\section{Resultados e Discussão}

Comecei aos poucos desenvolver minha base econômica, optei por cursar administração, uma disciplina técnica e de aplicação vasta. Tão logo, tive a oportunidade de trabalhar e paralelamente à graduação alinhar teoria com prática notando a diferença entre dois mundos distantes e complementares, de conhecer um conteúdo e aplicar no diadia.

Aos poucos comecei a ter uma dimensão de mundo que até então não conhecia, tive de aprender a servir, ouvir e a sentir que o ambiente influi nos resultados. Aos poucos fui 
entendendo a razão de tudo por aqui ter suas devidas proporções e distribuições exatas, unívocas, ao sentir inteiramente a sensação de estar em um lugar que impulsiona o desenvolvimento.

No primeiro ano me envolvi em projetos, comecei a utilizar meu tempo livre para aprendizados e constituí um período de extremo aproveitamento. Iniciei com um objetivo de conhecer o mundo com afinco em sua cultura, quis aprender uma nova língua e dar continuidade ao meu saber fazer.

Com quase três anos de curso concluídos, optei por fazer uma segunda graduação em paralelo, o Bacharelado em Ontopsicologia, buscando então uma formação técnica, mas também uma de caráter humanista.

Em meu trabalho tive inúmeros aprendizados e resultados, porém continuo sempre em busca de aperfeiçoamento e desenvolvimento buscando aprender coisas novas a cada dia. Fiz de 2015 um ano intenso, de muito trabalho e estudo, orientado por um objetivo final, que era fazer um intercambio na Itália. Após muito esforço tive a oportunidade por intermédio da Antonio Meneghetti Faculdade que possui parceria com a Universidade Per Stranieri di Perugia - Itália, de cursar língua e aprender sobre a cultura nesse país que é berço do humanismo ocidental.

Portanto, fiel ao meu projeto de vida, constituo minha base econômica, um saber fazer para tornar-me um protagonista responsável. Trilhando um percurso de formação pessoal e profissional frente às exigências do mundo contemporâneo.

\section{Considerações Finais}

Todo jovem deve ter um escopo claro de vida e tentar desenvolver aptidões que possam ser utilizadas no dia-dia. Ainda mais, o mundo está cada vez mais globalizado, por isso é necessário criar uma competência competitiva. A práxis de uma base econômica deve ser um dos primeiros princípios, para aos poucos ganhar liberdade de ser quem se é. Um jovem protagonista responsável é aquele que escolhe fazer de si uma existência única de projeto de vida com realização pessoal. O percurso de formação pessoal e profissional em resposta às exigências do mundo contemporâneo já começou e depende da forma como será desenvolvido. O máximo empenho nas coisas simples, o contínuo desenvolvimento e a humildade de aprender todos os dias são fatores determinantes para um crescimento sadio. 


\section{Referências}

BERNABEI, P. Os três pontos para entrar no mundo do trabalho. In: Psicologia Managerial. Vários autores. 3. ed. São Paulo: FOIL, 2011.

MENEGHETTI, A. Psicologia Empresarial. São Paulo: FOIL, 2011.

MENEGHETTI, A. Os Jovens e a Ética ôntica. Recanto Maestro: Ontopsicológica Editora Universitária, 2013.

MENEGHETTI, A. A Arte de Viver dos Sábios. Recanto Maestro: Ontopsicológica Editora Universitária, 2012.

MENEGHETTI, A. Arte Sonho e Sociedade. Recanto Maestro: Ontopsicológica Editora Universitária, 2015.

MENEGHETTI, A. Do Humanismo Histórico ao Humanismo Perene. Recanto Maestro: Ontopsicológica Editora Universitária, 2014.

MENEGHETTI, A. Nova Fronda Viresci: introdução à Ontopsicologia para Jovens. Recanto Maestro: Ontopsicológica Editora Universitária, 2014.

MENEGHETTI, A. Cultura e Educação: uma nova pedagogia para sociedade futura. Recanto Maestro: Ontopsicológica Editora Universitária, 2015. 